


\section{RItine $\mathbb{C}$ dh $\mathfrak{i}$ ften}

Son

\section{ช. (3.}

Dritter I

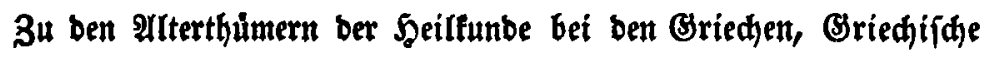
Inidififten, zur alten నumifgeididite.

Mit zoel \$lättern in Steinbrữ unb siner Rarte für ben zweiten Theil.

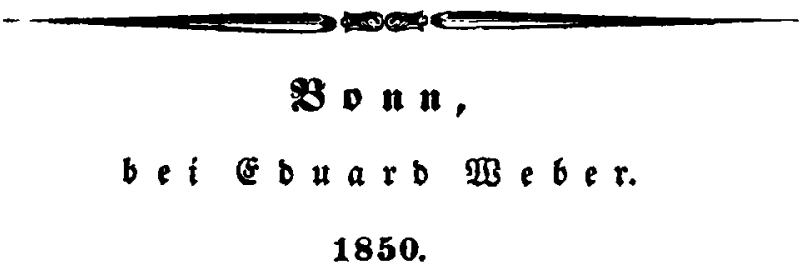




\section{Rreine Edyiften}

$\mathfrak{3} \mathfrak{H}$

Den Alterthümern Der Seilfunbe bei Den Grriecthen, Brriedif(d)e Snidhriften, zur alten Sunftgeidjidjte

bon

ชั. (3.)

Mit z̧wei Blăttetn in Steinbrud.

$\mathfrak{B} \mathfrak{\sim} \mathfrak{n}$,

bei cอ b a

1850. 
